\title{
THE CHARACTERISTICS OF OSL SIGNAL FROM QUARTZ GRAINS EXTRACTED FROM MODERN SEDIMENTS IN JAPAN
}

\author{
KAYOKO TOKUYASU ${ }^{1}$, KAZUHIRO TANAKA ${ }^{1}$, SUMIKO TSUKAMOTO ${ }^{2}$ and ANDREW MURRAY ${ }^{3}$ \\ ${ }^{1}$ Graduated school of Science and Engineering, Yamaguchi University, 1677-1 Yoshida, \\ Yamaguchi prefecture 753-8511, Japan \\ ${ }^{2}$ Leibniz Institute for Applied Geosciences, Geochronology and Isotope Hydrology, \\ Stilleweg 2, D-30655 Hannover, Germany \\ ${ }^{3}$ Nordic Laboratory for Luminescence Dating, Department of Earth Sciences, Aarhus University, \\ Risø DTU, DK-4000 Roskilde, Denmark
}

\begin{abstract}
Quartz grains from sediments in Japan are derived from complex mixtures of sources, including volcanic, plutonic, metamorphic and sedimentary rocks. We have measured the OSL signal of quartz grains from modern coastal sediments derived from different source rocks and compared these characteristics with the likely source. Each sample shows a different combination of various OSL components. It is concluded that the source rock affects the characteristics of the OSL components from quartz grains in Japanese sediments. By comparing the LM-OSL signals from volcanic sources with those from various source rocks, it can be deduced that quartz which has a higher fast component ratio is more suitable for dating. We also conclude that volcanic source areas should be avoided.
\end{abstract}

Keywords: SAR protocol, LM-OSL, OSL component, Japanese sediments, source rock

\section{INTRODUCTION}

Optically stimulated luminescence (OSL) dating using quartz has been successfully applied mainly to sediments from continental sources, where the quartz has experienced repeated cycles of erosion, transportation and deposition. On the other hand, problems have been reported for quartz originating from active belts (e.g. Indonesia, Italy, Japan, New Zealand and Peru). These include, very low OSL sensitivity and/or no fast component (Preusser et al., 2006; Westaway, 2009), age underestimation due to a short lifetime of the signal and anomalous fading (Bonde et al., 2001; Steffen et al., 2009; Tsukamoto et al., 2007).

There have not been many applications of quartz OSL dating to Japanese sediments. Tanaka et al. (2001) compared multiple aliquot additive dose (MAAD) and regenerative dose (MAR) protocols for quartz from fluvial terrace sediments; they observed very different equivalent doses $\left(D_{e}\right)$ from the two approaches. They also used a single aliquot regenerative dose (SAR) protocol for 48 single quartz grains for one sample and obtained widely scattered $D_{e}$ values. Some authors have reported that they could not use coarse grained quartz as a dosimeter, because their quartz showed no OSL signal (Kondo et al., 2007) or no fast component (Tsukamoto et al., 2007). Other authors have focused on loess which mainly originates from the Asian continent (Watanuki et al., 2003; 2005; Tsukamoto et al., 2003). They found that equivalent dose $\left(D_{e}\right)$ values tend to be underestimated due to the presence of the medium and slow 1 components (as defined by Jain et al., 2003; Component-2 in Watanuki et al., 2005) and assumed that these components originate from more local volcanic quartz. More recently, Tokuyasu et al. (in prep) obtained 20-40 ka from 25 quartz samples obtained from shallow marine sediments which had expected ages of 80-130 ka.

The characteristics of the quartz OSL components in Japanese sediments remain poorly known and it is not yet clear that reliable luminescence ages can be derived. It is also important to determine whether the characteristics of the quartz OSL signal depend on the source rock(s) and whether this affects the use of the SAR method. We report here on OSL signals from modern marine and lake sediments derived from different source rocks, and discuss the implications of these observations for dating. 


\section{SAMPLES}

Modern (recently deposited) samples were collected at 6 sites in total. The sediments from 5 sites are each derived from a single source rock type, but sediments from the $6^{\text {th }}$ (Ube) are from a mixture of source rocks. All samples were collected using PVC pipes to prevent light exposure during sampling and were sealed on-site. The material at each end of the pipe, which may have been exposed to light during collection, was discarded in the laboratory.

\section{Tazawa: volcanic rock source}

The Tazawa site is located in the Akita prefecture in the northern part of Honshu (Fig. 1). Sand was collected from the Tazawa Lake beach; these sediments are mainly composed of Tertiary volcanic rocks and Tamagawa Welded Tuffs which were erupted between 2 and 1 Ma (Oide et al., 1989). Hashimoto et al. (1986; 1987) obtained red TL Luminescence Colour Image (TLCI) from the quartz grains from the same site, which suggests the quartz grains are derived from volcanic rocks.

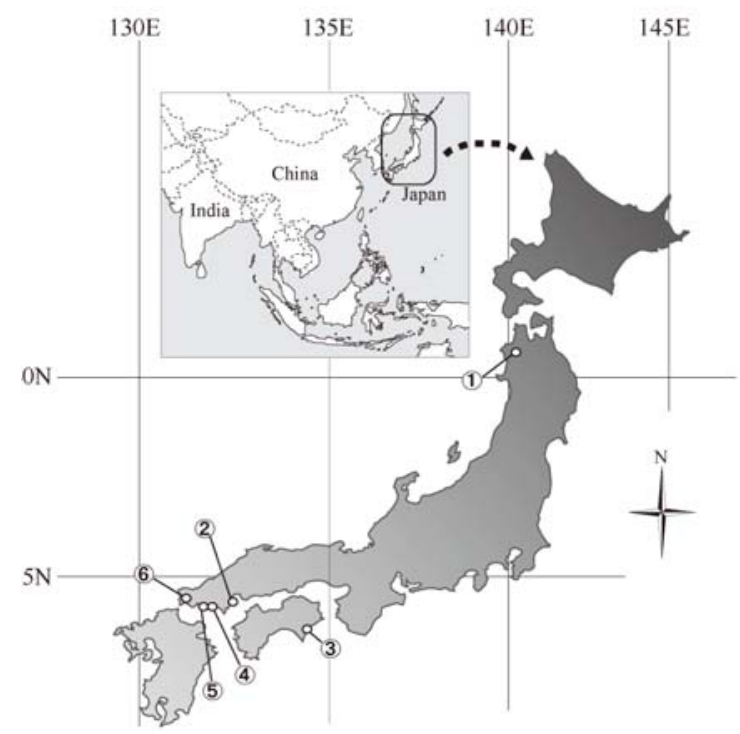

Fig. 1. Location map of sampling sites; (1) Tazawa, (2) Miyajima, (3) Muroto, (4) Kasado, (5) Mukojima, (6) Ube.

\section{Miyajima: granite rock source}

The Miyajima site is located at the Miya-jima island, Hiroshima Prefecture in the western part of Japan (Fig. 1). This island is composed of Hiroshima Granite ( $~ 82$ $\mathrm{Ma}$; K-Ar ages of biotite; Shibata and Ishihara, 1974). The coastal sand was collected from Hougaura beach in the northern part of the island, and can be reliably assumed to originate almost entirely from the Hiroshima Granite.

\section{Muroto: sedimentary rock source}

This sample was collected from the Ikumi beach located in the Muroto Peninsula, southeast of Shikoku (Fig. 1). The Muroto peninsula is located at the southern part of the Shimanto belt and composed mainly of sedimentary rock of including Tertiary sand stone and mudstone (Suyari et al., 1991).

\section{Kasado: metamorphic rock source (low-pressure type)}

The sample was collected from the Hanaguri beach, northwest of the Kasado-jima island, Yamaguchi Prefecture (Fig. 1). The Kasado-jima island is composed mainly of a low pressure type Cretaceous Ryoke metamorphic rocks, massive biotite granite and magmatitic biotite tonalite. In the northern area, the metamorphic rocks consist mainly of metapelite and metachart, with lesser crystalline limestone and matapsammite (Beppu and Okudaira, 2006). The peak metamorphic conditions for the northern and central area and for the southern area of Kasado-jima island are estimated $\sim 470^{\circ} \mathrm{C}$ at $200 \mathrm{MPa}$ and $\sim 550^{\circ} \mathrm{C}$ at $250 \mathrm{MPa}$, respectively (Beppu and Okudaira, 2006).

\section{Mukojima: metamorphic rock source (high-pressure type)}

The sample was collected from the Tanoura beach, southwest of the Muko-jima island, Yamaguchi Prefecture. This island is mainly composed of pelitic rocks of high pressure Sangun metamorphic rocks ( 260Ma; K-Ar ages; Nishimura et al., 1983), which includes a small amount of sandstone and basic rock. In the northern part of the island, intruded biotite granite rocks are exposed (Sawaki, 1985).

\section{Ube: mixture}

The coastal sand was collected from the beach close to the Maruo port in Ube city, Yamaguchi Prefecture (Fig. 1). This sediment is likely to be derived from at least five different types of source rocks from around this site, i.e. Tertiary sedimentary rocks including conglomerate, sandstone and mudstone. Serpentinite from Sangun metamorphic rocks and granites are also exposed (Igi et al., 1987).

All the samples were prepared by first sieving to between $75-125 \mu \mathrm{m}$, treated with $36 \%$ hydrochloric acid for 48 hours and with $20 \%$ sodium hydroxide for 24 hours. The density fraction between $2.63-2.68 \mathrm{~g} \cdot \mathrm{cm}^{-3}$ was then separated using sodium polytungstate solution, and etched with $23 \%$ hydrofluoric acid for 2 hours and with $20 \%$ hydrofluorosilicic acid over 7 days. The calibration quartz provided by Risø-DTU was also measured for comparison; it is known to be dominated by the fast component (Jain et al., 2008), the most suitable component for dating sediments when using the SAR protocol (Murray and Wintle, 2006). 


\section{INSTRUMENT AND OSL MEASUREMENTS}

All luminescence measurements were made with a Risø TL/OSL-DA-15 system (Bøtter-Jensen et al., 2003) equipped with a calibrated ${ }^{90} \mathrm{Sr} r{ }^{90} \mathrm{Y}$ beta source $(\sim 0.1$ $\mathrm{Gy} / \mathrm{s}$ ). Blue light emitting diodes (LEDs) were used for stimulation, and the luminescence signal was detected in the ultraviolet (UV) region through a $7.5 \mathrm{~mm}$ HOYA U340 filter. All luminescence measurements were carried out on coarse grained quartz $(75-125 \mu \mathrm{m})$ using preheats between 160 and $300^{\circ} \mathrm{C}(10 \mathrm{~s})$ and blue light stimulation at $125^{\circ} \mathrm{C}$ for $40 \mathrm{~s}$ with the single aliquot regenerativedose (SAR) procedure (Murray and Wintle, 2000), which is shown in Table 1. Cut-heat was set to $40^{\circ} \mathrm{C}$ below the preheat temperatures (from 120 to $260^{\circ} \mathrm{C}$ ). At the end of each measurement cycle a blue light stimulation at $280^{\circ} \mathrm{C}$ for $40 \mathrm{~s}$ was conducted to prevent signal carry over to the next cycle. At the end of the SAR sequence, the same regeneration dose as the first regeneration dose (22 Gy) was repeated to check whether the sensitivity corrected
Table 1. Experimental flow chart for De estimation and LM-OSL measurement.

\begin{tabular}{cl}
\hline Step & Treatment \\
\hline 1 & Give dose $(0$ Gy if natural) \\
2 & Preheat at $160-300^{\circ} \mathrm{C}$ for $10 \mathrm{~s}$ \\
3 & OSL measurement at $125^{\circ} \mathrm{C}$ for $40 \mathrm{~s} \rightarrow L_{x}$ \\
4 & Give test dose \\
5 & Cut heat at $120-260^{\circ} \mathrm{C}$ for $10 \mathrm{~s}$ \\
6 & OSL measurement at $125^{\circ} \mathrm{C}$ for $40 \mathrm{~s} \rightarrow T_{x}$ \\
7 & Hot bleach by Blue-LED at $280^{\circ} \mathrm{C}$ for $40 \mathrm{~s}$ \\
8 & Repeat from step1 to 7 \\
9 & Give dose to 88 Gy \\
10 & Preheat at $260^{\circ} \mathrm{C}$ for $10 \mathrm{~s}$ \\
11 & LM-OSL measurement $\left(125^{\circ} \mathrm{C}\right.$ for $\left.1000 \mathrm{~s}\right)$ \\
\hline
\end{tabular}

OSL $\left(\mathrm{L}_{\mathrm{x}} / \mathrm{T}_{\mathrm{x}}\right)$ was reproducible (recycling ratio). After a conventional SAR cycle, Linear Modulated (LM) OSL was measured by linearly increasing the power of the LEDs from 0 to $\sim 78 \mathrm{mWcm}^{-2}$. LM-OSL measurements were made for $1000 \mathrm{~s}$ at $125^{\circ} \mathrm{C}$ after irradiating the aliquots with $88 \mathrm{~Gy}$ and preheated at $260^{\circ} \mathrm{C}$ for $10 \mathrm{~s}$. The resulting LM-OSL curve was fitted with the following
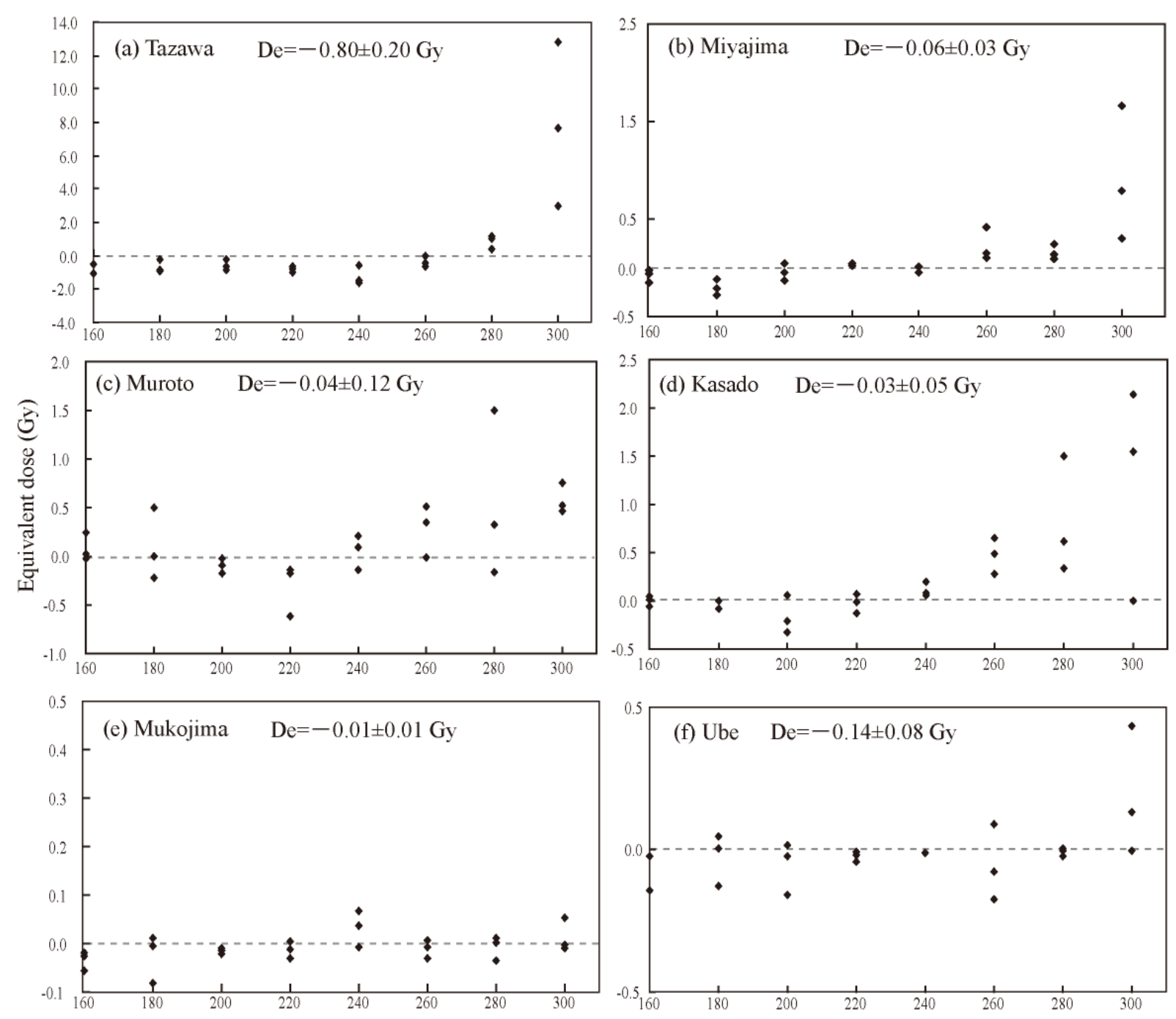

Fig. 2. $D_{e}$ estimates $(n=24)$ as a function of preheat temperature. The average $D_{e}(n=15)$ given on each diagram is based on the temperature range 160 to $240^{\circ} \mathrm{C}$. 
equation to separate into $i$ different components:

$L(t)=\sum A_{i} b_{i}\left(\frac{t}{P}\right) \exp \left(\frac{b_{i} t^{2}}{2 P}\right)$,

where $A_{i}$ is the amplitude, $b_{i}$ is the detrapping probability (proportional to photoionization cross section $\sigma_{i}$ ) and the maximum light intensity $I_{0}\left(b_{i}=\sigma_{i} I_{0}\right), P$ is the total observation time and $L(t)$ is the OSL signal at time $t$ (Bulur, 1996).

\section{OSL CHARACTERISTICS OF QUARTZ GRAINS FROM SEDIMENTS IN JAPAN}

The $D_{e}$ values of the modern beach sediments were obtained using the SAR protocol with different preheat temperatures between 160 and $300^{\circ} \mathrm{C}$. Fig. 2 shows the $\mathrm{D}_{\mathrm{e}}$ values at different preheat temperatures. At each temperature, 3 aliquots were used; for $D_{e}$ estimation, the first $0.8 \mathrm{~s}$ of stimulation was integrated, and the $0.96-1.76 \mathrm{~s}$ integral subtracted as background. All the $D_{e}$ values are close to zero for preheat temperatures between 160$240^{\circ} \mathrm{C}$, indicating that the quartz grains were well bleached (see Fig. 2 and Table 2). However, the $D_{e}$ values increase for preheats above $260^{\circ} \mathrm{C}$. This increase can be explained by thermal transfer (Aitken, 1998). Fig. 3 shows the sensitivity change through the SAR cycles $\left(T_{i} / T_{n}\right)$ for all samples using 6 aliquots, for $260^{\circ} \mathrm{C}$ preheats. The sensitivity of the OSL signal increased by 2-3 times during the SAR cycles for the samples from volcanic rock source (Tazawa), granite rock source (Miyajima), high-pressure metamorphic rock source (Mukojima) and low-pressure metamorphic rock source (Kasado), however those samples from sedimentary rock

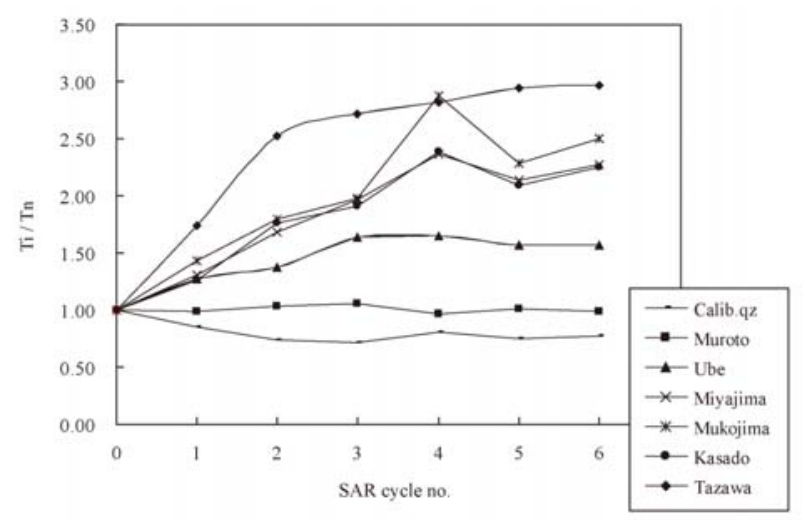

Fig. 3. $T_{i} / T_{n}$ ratio preheated at $260^{\circ} \mathrm{C}$ for $10 \mathrm{~s}$ as a function of the $S A R$ cycle.

Table 2. Results of experimental measurements. The $D_{e}$ values are estimated average from 160 to $240{ }^{\circ} \mathrm{C}$ preheat temperature $(n=15)$.

\begin{tabular}{|c|c|c|c|c|c|}
\hline Sample & Source & $D_{e}\left(160-240^{\circ} \mathrm{C}, \mathrm{Gy}\right)$ & Dose recovery ratio & Recycling ratio & R0 /RN (\%) \\
\hline Tazawa & volcanic & $-0.80 \pm 0.20$ & $0.98 \pm 0.14$ & $0.81 \pm 0.13$ & 155 \\
\hline Miyajima & granitic & $-0.06 \pm 0.03$ & $0.91 \pm 0.01$ & $1.12 \pm 0.05$ & 21 \\
\hline Muroto & sedimentary & $-0.04 \pm 0.12$ & $0.92 \pm 0.04$ & $0.97 \pm 0.03$ & 54 \\
\hline Kasado & metamorphic & $-0.03 \pm 0.05$ & $1.00 \pm 0.18$ & $1.03 \pm 0.04$ & 6 \\
\hline Mukojima & metamorphic & $-0.01 \pm 0.01$ & $0.98 \pm 0.01$ & $1.17 \pm 0.05$ & 210 \\
\hline Ube & mixed & $-0.14 \pm 0.08$ & $1.03 \pm 0.13$ & $0.98 \pm 0.01$ & -65 \\
\hline
\end{tabular}

Table 3. Summary of OSL components of quartz grains from sediments in Japan.

\begin{tabular}{|c|c|c|c|c|c|}
\hline Sample & OSL components & $\begin{array}{l}\text { Detrapping probability } \\
\qquad\left(\mathbf{s}^{-1}\right)\end{array}$ & $\begin{array}{c}\text { Photoionisation } \\
\text { Cross Section } \\
\left(10^{-18} \mathrm{~cm}^{2}\right)\end{array}$ & $\begin{array}{l}\text { Relative Cross Section } \\
\text { to fast component }\end{array}$ & $\begin{array}{l}\text { Relative Intensity to } \\
\text { fast component }\end{array}$ \\
\hline \multirow{2}{*}{ Calib. Qz } & Fast & 6.1 & 32.8 & 1 & 1 \\
\hline & Medium & 1.2 & 6.4 & 0.20 & 0.26 \\
\hline \multirow{2}{*}{ Tazawa } & Medium & 1.4 & 7.5 & 0.31 & - \\
\hline & Slow1 & 0. & 2.3 & 0.09 & - \\
\hline \multirow{2}{*}{ Miyajima } & Fast & 4.9 & 26.3 & 1 & 1 \\
\hline & Medium & 1.0 & 5.4 & 0.21 & 1.05 \\
\hline \multirow{2}{*}{ Muroto } & Fast & 3.3 & 17.6 & 1 & 1 \\
\hline & Medium & 0.7 & 3.9 & 0.22 & 1.30 \\
\hline \multirow{2}{*}{ Kasado } & Fast & 5.5 & 29.4 & 1 & 1 \\
\hline & Slow 1 & 0.4 & 2.2 & 0.07 & 0.43 \\
\hline \multirow{2}{*}{ Mukojima } & Fast & 4.3 & 23.4 & 1 & 1 \\
\hline & Medium & 0.9 & 4.8 & 0.20 & 2.00 \\
\hline \multirow{2}{*}{ Ube } & Fast & 6.3 & 33.9 & 1 & 1 \\
\hline & Medium & 1.6 & 8.75 & 0.26 & 0.82 \\
\hline \multirow{3}{*}{ Jain et al. (2003) } & Fast & - & 23.2 & 1 & - \\
\hline & Medium & - & 5.6 & 0.24 & - \\
\hline & Slow 1 & - & 1.3 & 0.06 & - \\
\hline \multirow{2}{*}{ Singarayer and Bailey (2003) } & Fast & - & 25.0 & 1.00 & - \\
\hline & Medium & - & 5.9 & 0.24 & - \\
\hline
\end{tabular}


source (Muroto) and mixture of source rocks including sedimentary rock (Ube) showed no significant sensitivity change. This may suggest that the quartz grains from sedimentary rock have already been sensitised. The recycling ratio $\left(L_{5} / T_{5}\right) /\left(L_{1} / T_{1}\right)$ is satisfactory in 4 out of 6 samples, suggesting the sensitivity correction using a test dose is performing well in the cases. However, the recy- cling ratios from volcanic rock source and high-pressure metamorphic rock source, of $0.81 \pm 0.13$ and $1.17 \pm 0.05$, respectively, are not so satisfactory. $\mathrm{R}_{0} / \mathrm{R}_{\mathrm{N}}$ ratios from the 2 samples are $155 \%$ and $210 \%$, respectively, indicating a much higher level of recuperation in these samples (Table 2).
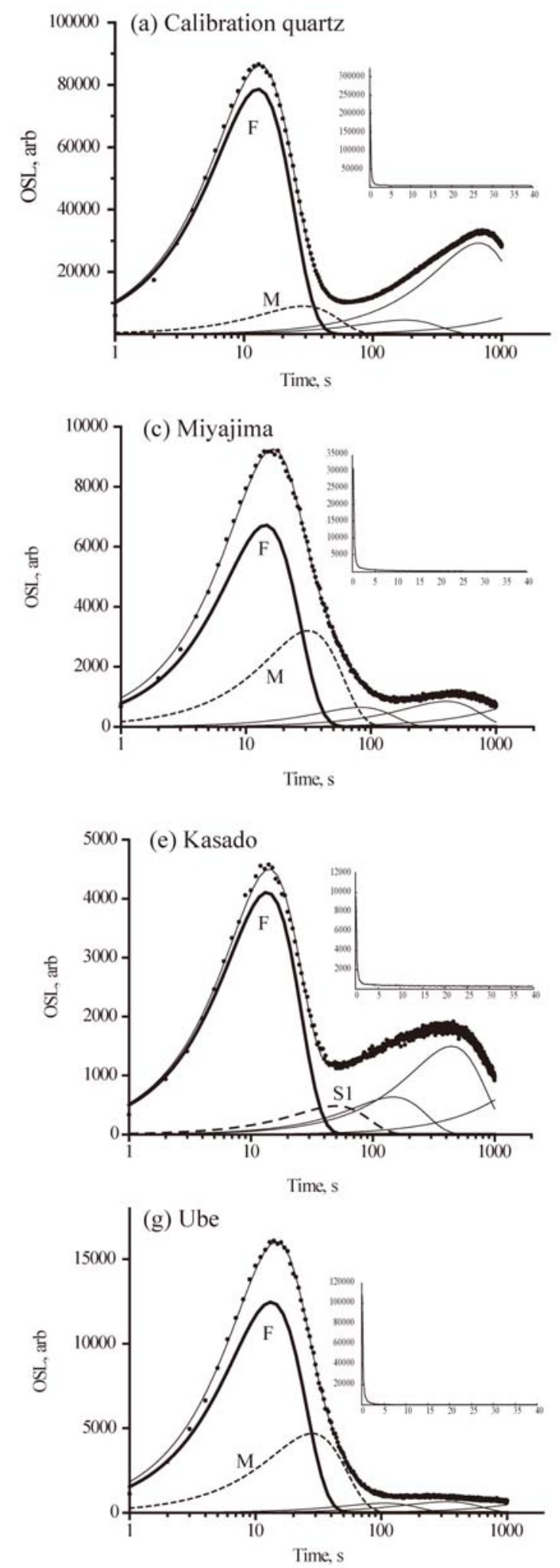


Fig. 4. LM-OSL signal from $88 \mathrm{~Gy}$ irradiated aliquots, after a preheat to $260^{\circ} \mathrm{C}$ for $10 \mathrm{~s}$. Inset shows the decay curve of 22 Gy irradiated aliquot of each sample, after the same preaheat. 
A dose recovery test was conducted for all samples using 3 aliquots for Miyajima and Ube samples, and 6 aliquots for other samples. The aliquots were bleached with blue light without heating, and then given a beta dose of 33 Gy. The SAR protocol was applied, using a $260^{\circ} \mathrm{C}$ preheat, to test whether the given dose was successfully recovered. All samples, including those from Tayawa and Mukojima, gave a recovered/given dose ratio close to unity (within $\pm 10 \%$; Table 2 ), showing that our SAR protocol is able to determine a dose given to these samples before any heating.

Fig. 4 shows the LM-OSL curves of the quartz grains from Risø calibration quartz and the 6 modern Japanese samples. The LM-OSL signals were fitted with between 4 and 6 components (usually fast, medium and 2-4 slow components). A summary of the results of this fitting process is shown in Table 3. Each sample shows a different combination of various OSL components. In particular, the sample from the volcanic source area does not have a detectable fast component but only a medium and a strong slow-1 component (using the definition of Jain et al., 2003). As a result, the continuous wave (CW) OSL curve of this sample shows a slower decay compared to that of calibration quartz (Fig. 4), and significant thermal transfer at higher preheat temperatures above $260^{\circ} \mathrm{C}$ (Fig. 2). According to Tsukamoto et al. (2007) these luminescence characteristics are typical of volcanic quartz; they also found that the OSL signal from volcanic quartz fades. The fast component is present in all our other samples, although all have a larger relative medium component contribution compared to calibration quartz. The low pressure metamorphic sample is an exception to this; it has no detectable medium component. It is interesting to note that in this sample one can expect that the fast component was sensitised during the metamorphic process (Tsukamoto et al., 2010). Poor recycling ratios, $0.81 \pm 0.13$ and $1.17 \pm 0.05$ were obtained from the Tazawa and Mukojima samples, respectively; these two samples have the smallest relative contribution of the fast component (Table 3). All the other samples show a relatively strong fast component, and these are the samples which show satisfactory dose recovery and recycling ratios.

\section{CONCLUSION}

This paper compares the OSL components of quartz grains derived from different source rock areas: volcanic, granitic, metamorphic (both high and low pressure type), sedimentary and mixed. Each sample shows a different combination of the various OSL components and this resulted in different performance in the SAR protocol. The quartz samples which showed dominant fast component (Ube and Kasado) showed best recycling and dose recovery ratios, which suggests these samples are suitable for OSL dating using SAR. On the other hand, the samples with no or only a small fast component (volcanic and high pressure metamorphic source) showed good dose recovery ratio but a poor recycling ratio and greater sensitivity changes; these samples are unlikely to be suitable for OSL dating.

\section{ACKNOWLEDGEMENTS}

We thank Dr. Ryuta Hataya, the Central Research Institute of Electric Power Industry, for permission to prepare samples, Dr. Jan-Pieter Buylaert, Aarhus University, for his help and valuable advice and three anonymous reviewers for making further improvements to the manuscript.

\section{REFERENCES}

Aitken MJ, 1998. An introduction to optical dating. London, Oxford Science Publications: 267pp.

Beppu Y and Okudaira T, 2006. Geology and metamorphic zonation of the Ryoke metamorphic belt on Kasado-jima Island, SW Japan. Journal of Mineralogical and Petrological Sciences 101: 240-253, DOI 10.2465/jmps.101.240.

Bonde A, Murray AS and Friedrich WL, 2001. Santorini: luminescence dating of a volcanic province using quartz? Quaternary Science Reviews 20(5-9): 789-793, DOI 10.1016/S0277-3791(00)00034-2.

Bulur E, 1996. An alternative technique for optically stimulated luminescence (OSL) experiment. Radiation Measurements 26(5): 701 709, DOI 10.1016/S1350-4487(97)82884-3.

Bøtter-Jensen L, Andersen CE, Duller GAT and Murray AS, 2003. Developments in radiation stimulation and observation facilities in luminescence measurements. Radiation Measurements 37(4-5): 535-541, DOI 10.1016/S1350-4487(03)00020-9.

Hashimoto T, Hayashi Y, Koyanagi A and Yokosaka K, 1986. Red and blue colouration of thermoluminescence from natural quartz sands. Nuclear Tracks and Radiation Measurements 11(4-5): 229-235, DOI 10.1016/1359-0189(86)90039-7.

Hashimoto T, Yokosaka K and Habuki H, 1987. Emission properties of thermoluminescence from natural quartz - blue and red TL response to absorbed dose. Nuclear Tracks and Radiation Measurements 13(1): 57-66, DOI 10.1016/1359-0189(87)90008-2.

Igi S, Murakami N and Okubo M, 1987. Regional geology of Japan. Part 7 Chugoku. Kyoritsu Shuppan: 290pp (in Japanese).

Jain M, Murray AS and Bøtter-Jensen L, 2003. Characterisation of bluelight stimulated luminescence components in different quartz samples: implications for dose measurement. Radiation Measurements 37(4-5): 441-449, DOI 10.1016/S1350-4487(03)00052-0.

Jain M, Choi JH, and Thomas PJ, 2008. The ultrafast OSL component in quartz: Origin and implications. Radiation Measurements 43(26): 709-714, DOI 10.1016/j.radmeas.2008.01.005.

Kondo R, Tsukamoto S, Tachibana H, Miyairi Y and Yokoyama Y, 2007. Age of glacial and periglacial landforms in northern Hokkaido, Japan, using OSL dating of fine grain quartz. Quaternary Geochronology 2(1-4): 260-265, DOI 10.1016/j.quageo.2006.06.015.

Nishimura Y, Nakamura E and Hara I, 1983. K-Ar ages of Sangun metamorphic rocks in Yamaguchi Prefecture and their geologic significance. Journal of the Japanese Association of Mineralogists, Petrologists and Economic Geologists 78: 11-20.

Murray AS and Wintle AG, 2000. Luminescence dating of quartz using an improved single-aliquot regenerative-dose protocol. Radiation Measurements 32(1): 57-73, DOI 10.1016/S1350-4487(03)000544.

Murray AS and Wintle AG, 2006. A review of quartz optically stimulated luminescence characteristics and their relevance in singlealiquot regeneration dating protocols. Radiation Measurements 41(4): 369-391, DOI 10.1016/j.radmeas.2005.11.001.

Oide K, Nakagawa $\mathrm{H}$ and Kanisawa S, 1989. Regional geology of Japan. Part 2 Tohoku. Kyoritsu Shuppan: 338pp.

Preusser F, Ramseyer K and Schluchter C, 2006. Characterisation of low OSL intensity quartz from the New Zealand Alps. Radiation Measurements 41(7-8): 871-877.

Sawaki T, 1985. Corundom-bearing politic hornfels in the Hofu area, Yamaguchi Prefecture. The Journal of Geological Society of Japan 91: 719-722 (in Japanese).

Singarayer JS and Bailey RM, 2003. Further investigations of the quartz optically stimulated luminescence components using linear modulation. Radiation Measurements 37(4-5): 451-458, DOI 10.1016/S1350-4487(03)00062-3. 
Shibata K and Ishihara S, 1974. K-Ar ages of biotites across the central part of the Hiroshima granite. The Journal of Geological Society of Japan 80: 431-433 (in Japanese).

Steffen D, Preusser F and Schlunegger F, 2009. OSL quartz age underestimation due to unstable signal components. Quaternary Geochronology 4(5): 353-362.

Suyari K, Iwasaki M and Suzuki T, 1991. Regional geology of Japan. Part 8 Shikoku. Kyoritsu Shuppan: 226pp.

Tanaka T, Hataya R, Spooner NA, Daniele G Q, 2001. Optical dating of river terrace sediments from Kanto Plains, Japan. Quaternary Science Reviews 20(5-9): 825-828.

Tokuyasu K, Thiel C, Buylaert JP, Tsukamoto S, Murray AS and Tanaka $\mathrm{K}$, in prep. Testing the potential of quartz and feldspar luminescence dating to MIS5, Japanese marine deposits.

Tsukamoto S, Rink WJ and Watanuki T, 2003. OSL of tephric loess and volcanic quartz in Japan and an alternative procedure for estimating $\mathrm{D}_{\mathrm{e}}$ from a fast OSL component. Radiation Measurement 37(45): 459-465, DOI 10.1016/S1350-4487(03)00054-4.

Tsukamoto S, Murray AS, Huot S, Watanuki T, Denby PM and BøtterJensen L, 2007. Luminescence property of volcanic quartz and the use of red isothermal TL for dating tephras. Radiation Measurements 42(2): 190-197, DOI 10.1016/j.radmeas.2006.07.008.

Tsukamoto S, Nagashima K, Murray AS and Tada R, 2010. Variations in OSL components from quartz from Japan Sea sediments and the possibility of reconstructing provenance. Quaternary International, submitted.

Watanuki T, Murray AS, and Tsukamoto S, 2003. A comparison of OSL ages derived from silt-sized quartz and polymineral grains from Chinese loess. Quaternary Science Reviews 23(10-13): 991997, DOI 10.1016/S0277-3791(03)00053-2.

Watanuki T, Murray AS, and Tsukamoto S, 2005. Quartz and polymineral luminescence dating of Japanese loess over the last $0.6 \mathrm{Ma}$ : Comparison with an independent chronology. Earth and Planetary Science Letters 240(4-5): 774-789, DOI 10.1016/j.eps1.2005.09.027.

Westaway KE, 2009. The red, white and blue of quartz luminescence: A comparison of $\mathrm{D}_{\mathrm{e}}$ values derived for sediments from Australia and Indonesia using thermoluminescence and optically stimulated luminescence emissions. Radiation Measurements 44(5-6): 462-466, DOI 10.1016/j.radmeas.2009.06.001. 